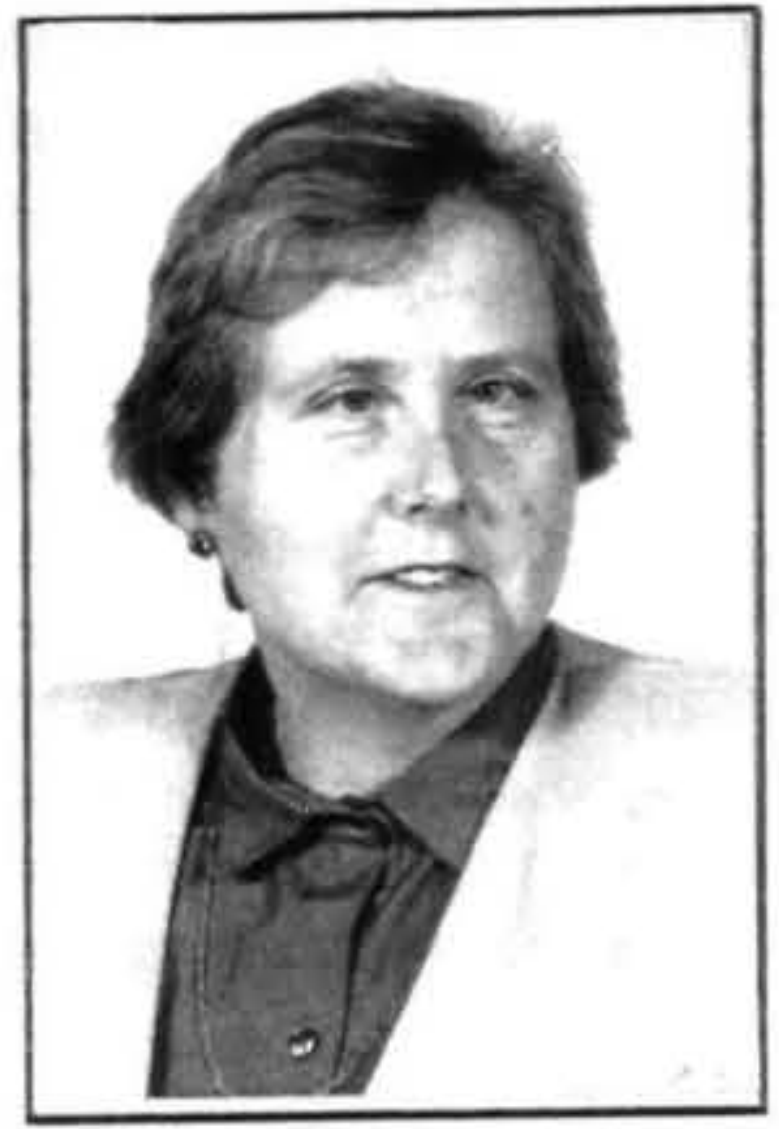

\title{
DISABILITY ON THE AGENDA THE FUTURE OF WORK FOR DISABLED PEOPLE
}

\author{
Robyn Hunt \\ Workbridge
}

\begin{abstract}
This paper will use findings of study in the UK as a Nuffield Travel Bursar to discuss the implications of some labour market developments for disabled people. In the course of the discussion old and new approaches to disability and their effect on relationships with the labour market will be explored. Three models of the relationship between disabled people and society are advanced, the charity, medical and social models. Implications of these models, and changes in the labour market are discussed, and some future research options outlined.
\end{abstract}

During the northern hemisphere summer of this year,as a Nuffield Travel Bursar in the UK, I studied the future of work for disabled people. My study included looking at wider issues such as demographic and labour market trends. I planned to study creative policies and programmes in open and supported employment for disabled people, and to look at some education issues, not dealt with in this paper.

Because of the importance of underlying philosophical assumptions about the meaning of disability on the development of labour market policies and the delivery of vocational services this area was also an important focus. My objective was to raise issues for discussion, rather to find hard and fast answers to particular questions.

\section{Background}

Despite significant changes in the labour market during the last decade my professional and personal involvement in the disability community had indicated that there was only a tenuous connection between the wider disability community and the current and future changes in the labour market. The central position of work in the widest sense as a key to the empowerment of disabled people is not always recognised in the disability community. Paid work and the resulting access to economic and social benefits and improved access to the political system are crucial.

It is also important for disability to be legitimised as part of the mainstream labour market and included alongside other equity issues such as gender and race for, as business writer and futurist Charles Handy says "What does not get counted does not count." (The Empty Raincoat : 219 .) He applies that statement to money, but it could equally be applied to people. People who make an economic contri- bution of whatever kind need to be recognised alongside other people and other contributions.

This paper draws heavily on personal interviews I conducted with a wide range of professionals working in my chosen areas. I also spoke to activists with disabilities working in these areas. The object was to take a broadbrush approach to the issues rather than focus on one or two programmes. I structured interviews loosely around a set of questions designed before I left New Zealand, not as a strict research tool, but rather as a framework to obtain reasonably consistent information.

\section{Disabled people}

In looking at the current situation it is necessary to explore some fundamental considerations. The philosophical standpoint from which disability is viewed will determine, whether consciously or not, the nature of policy in relation to disabled people in the labour market, and the nature of services available to them, and the success or otherwise of forces for change. An understanding of different approaches is therefore essential as a basis for discussing labour market issues as they apply to disabled people.

Throughout this paper I use the term 'disabled people,' contrary to current New Zealand usage which is usually 'people with disabilities.' This is because the term is not only the acceptable one in the UK, but is most commonly used by those thinkers and writers who are at the leading edge of change there.

We know that we do not just happen to have a disability, or that we are people first; our disabilities are essential parts of self, to be affirmed and celebrated, not denied or relegated to an appendage, and as such we demand 
to be called disabled people" (Oliver, 1992).

In rejecting the term most commonly used in New Zealand, Oliver is asserting identity for a group of people usually considered as a group sharing similar characteristics in relation to the labour market - if they are considered at all in the making of mainstream labour market policy.

A recent New Zealand example of a lack of inclusion of this group in mainstream labour market policy deliberations is the interim report of the Employment Task Force where disabled people do not warrant a mention despite the contribution to the consultation process by Workbridge and the Assembly of People with Disabilities.

This invisibility is also evident in New Zealand by the lack of consistent national data collection by such measures as the national census or the household labour force survey. This absence brings us back to the philosophical considerations which underlie the lack of inclusion.

\section{Three models}

The relationship between disabled people and the wider society may be appreciated using three models: the charity, medical and social. Each will be addressed in turn.

The UK and New Zealand both share the charity model of disability. In the UK I found it to be much more evident than in New Zealand, partly because regulations governing charities are stricter there, constraining their abilities to lobby government, but also partly because of historical factors.

The charity model is based on the premise that individuals within society choose to give up something, - to 'make a contribution' to a charity- in contrast to a rights based approach where everyone gives up something. The rights based approach assumes that the relationship between disabled and non-disabled people will move towards one of equal power - of empowerment for disabled people. Charity is based on an unequal power relationship, the giver has choice, the receiver does not. Gratitude is often expected, and some charitable causes are chosen more than others.

It became evident during my study that charity created barriers to employment for disabled people. Employment services in the UK are often charities which have to raise money to function. They are forced to confront the paradox of needing to enlist corporate assistance to "help" people, while trying to persuade the same corporates that they should employ the skilled and talented people on their registers. Taking such opposing approaches towards the same group of people gives mixed messages to employers and the community at large, which effects the degree of seriousness with which disabled people are seen as labour market participants.

Hand in hand with charity one often finds the medical model, one which disabled people struggle hard to escape from. This model assumes that disability is caused by psychological or physiological abnormality, and this abnormality is the primary focus of attention. The medical model leads to disabled people being seen as individual 'cases' of disease or illness needing to be cured. This is not always possible or indeed desirable, and is seen by many disabled people as denying their human dignity. It is further complicated by the position of medics and paramedics as gatekeepers to resources and services in areas such as employment where they may not have the breadth of knowledge needed to make appropriate judgements.

The social model of disability is closely associated by Oliver and others to the assertion of identity. This model underpins much of the progressive thinking in consideration of disability policy, and is equally applicable to labour market considerations. The social model sees disability as a social construction. This means that it is the surrounding physical and social environment which disadvantages disabled people more than any physical, sensory, intellectual or psychiatric condition. This model focuses on the problems faced by disabled people and places these problems in the social context rather than centring them in the individuals themselves. An example is the provision of physical access in the form of ramps, doorways, toilets, lighting, and signage etc, rather than expecting the individual to procure a wheelchair which will climb steps, although such things are available to those who can afford them.

The implications of all of this for the labour market are that disabled people are not taken seriously enough. Medical and charity considerations assume they are more helpless and less productive than is actually the case. Those models get in the way of clear application of the social model which can work in a systematic way to enable the diverse group of people with disabilities to contribute more fully.

\section{Participation in the labour market}

When asked whether or not disabled people should aspire to paid work, most people interviewed said that they should have a choice.

When asked if they would ascribe the same choice to other members of the community there was less clarity. Some admitted that they would not, although most thought there should be a right to work. This indicates a certain ambivalence in attitudes towards disabled people and paid work. Because of the more welfare oriented British society there seemed to be less of the emphasis on work for disabled people than I found in the United States during a visit last year.

Because of the strong paternalistic legacy from the past, among the larger and more powerful charities, more evident in the UK than in New Zealand, there is a philosophy which says that work is not central because not 
everyone can work. Activists have also concentrated on an adequate income rather than focusing on work directly.

However Charles Handy describes work in 'The Empty Raincoat,' as providing the structure of our lives, and as an indicator of our value. Therefore work must be an issue for disabled people. Radical thinkers such as Colin Bames, social researcher at Leeds University, take the view that in the modern capitalist state everybody who wants to participate and avail themselves of their rights must also accept their responsibility to contribute, although he would define economic contribution in very broad terms. This includes voluntary work, and the contribution of people who employ their own attendant care, even if the cost is met by the state.

Some respondents take the view that the Treasury approach to the issue of disabled people and employment currently prevailing in the British Government, namely that disabled people gaining work would simply displace other non-disabled workers. It could be argued that the higher benefit payments sometimes made to disabled people to account for the extra cost of disability means that the reverse could be true.

In the UK disabled people are unemployed in large numbers, earn less than their non-disabled peers, and only a small percentage are employed on the open labour market - similar conditions prevail in New Zealand.

\section{Demographics}

During the 1980s there was optimism about the demographic trend towards an ageing population during the ' $90 \mathrm{~s}$ and beyond which would create opportunities for previously disadvantaged groups to participate in the labour market. This was seen as an opportunity for disabled people because there would be fewer people of working age as a result of the greater number of older people, and disabled people would be more in demand. However the recession experienced during the late 1980 s and the early years of this decade, and the resulting high unemployment, dashed hopes of new opportunities. Coupled with this and the demand for higher skill levels, and the lag in achieving education and training gains has meant that where opportunities did exist they could not always be taken up. This is a problem we are beginning to experience in New Zealand during the economic recovery. Workbridge currently has a register of 40000 people, $62 \%$ of whom have no formal qualifications. We currently have vacancies, especially in the larger cities, which we cannot fill. Demographic trends can be explored and exploited, with the caution that outside factors such as recession could negate any benefits.

\section{Benefits}

As in most western countries discussions about benefits in the UK has been largely focused on sustaining an adequate income. While the debate about work in relation to benefits has been low key, Barnes takes the view that benefits which are not tied to integration into the workplace in some form should not be acceptable.

As in New Zealand there are many benefit disincentives; one British example is that part-time work is almost impossible unless the income earned is low enough to be termed 'theraputic earnings', which is an interesting concept.

Reliance on benefits and the adoption of a dependent role to get them has created the same dependency trap as in New Zealand, and there are some, such as professor Michael Oliver of Greenwich University, lecturer in disability studies, who accept that the creation of a culture of dependency has been anything but a beneficial spinoff from the welfare state, and that this unhealthy dependency should be rejected by disabled people themselves.

\section{The changing face of the labour market}

Charles Handy and Susan Lonsdale, social policy analysts, both referred to the problem of more work being done by fewer and fewer people, making higher demands on the individual in terms of productivity. The work is also increasingly highly skilled. This trend created difficulties for more people than disabled people. However there are problems surrounding productivity that are more than simply the perceptions of prejudice. The simple fact is, as Sally French, writer and academic described it (Swain et al, 1993), that no matter how highly skilled someone is, or how much enabling technology they have, their output may still not be the same as a non-disabled person. This of course will vary with disability type.

The solution suggested by both Handy and Lonsdale is the future possibility of sharing paid available work around more among the general population. The small elite group may be prepared to share out more work for less money, but benefiting by other advantages related to lifestyle. However to achieve this may be difficult in the modem free market economy requiring what could be an unacceptable degree of intervention.

There would appear to be little evidence of voluntary change in that direction so far. If such change did take place it could remove the difficulty of disabled people taking more time to produce the same results.

Coupled with shrinking work are shrinking communities. Communities are increasingly separate from each other as the working elite use different services and become separate from other strata of society. Groups know less and less about each other, and this Handy says, could further separate disabled people from the rest of society.

Organisations are changing shape, becoming smaller and flatter, with a core of highly skilled permanent staff, and other skills bought in as they are needed. Some of the functions no longer included in the central core are those 
with the least skills, such as cleaners. Because of the lower qualification level of disabled people, often due to educational disadvantage, there is a concern that they will remain on the expendable fringe of the labour market in disproportionate numbers.

Lifelong learning has not taken root as a concept in either New Zealand or in the UK in the disability community. Segregated training is still common in the UK, and inclusion in mainstream training has not yet been achieved here. Retraining for people trained in jobs which are disappearing is an issue, claimed not to be so prevalent in the UK, but that may be because theoretically at least there are still reserved occupations such as car park and lift attendants, and blind switchboard operators and typists still appear to be common. Multi-skilling, which began to disadvantage disabled people in New Zealand with the public sector reforms of the past decade, was not anticipated or acted upon by disability lobby organisations. Organisations in the UK are larger than in New Zealand and seem to be able to accommodate at least some social 'costs' more readily. It is interesting to note that in the UK more disabled people are placed with larger employers whereas in New Zealand most are placed with small employers.

\section{Technology and changing work practices}

New technology has benefited disabled people in many ways, not all of them have been hi-tech either - the humble highlighter has been of great value to some of us, for example. But some people are now beginning to think about the implications of technology use and questioning some of the terminology and the concepts behind them. They believe that the 'compensatory' advantages of much of the new technology have yet to be realised in employment growth among the disabled population. They claim that the majority of the disabled population currently employed are in low grade manual occupations. There is also some unease around the notion that technology has been seen to 'correct' the 'deficit' of the impaired individual, a quick 'deficit fixit', rather than the prime focus being on the impact of technology on employment barriers, (physical and attitudinal) and the role of technology in the workplace generally.

New technology has been seen as the 'saviour' of disabled people, it may also be used to create new disability stereotypes, the blind telemarketer, the wheelchair using computer programmer are just two examples. This new ghetto is based on disability type rather than talent, skills and preference. If homeworking is added to that mix then disabled people could become even more individualised and marginalised.

However there is some light in the gloom. Oliver, for example, is optimistic about the developments in workplace reform, the democratisation of the workplace, the focus on co operation rather than competition, and the emphasis on teamwork, which provides the opportunity for disabled people to balance their skills and talents, and productivity and other difficulties they may experience in relation to disability,

Equal Employment Opportunities initiatives are also another obvious tool, which has the potential to develop a balance between the individual workplace needs of disabled people, and the systematic but flexible organisational response needed.

\section{Future research}

Changes in the labour market can be seen as opportunities or threats, depending on how well prepared the disability community is to meet them. Change will occur if there is a mindshift among disabled people, the disability community and the wider community, which may involve the rejection of the dependency model in favour of a more realistic inter-dependency approach.

New Zealand has a positive advantage over the UK in our new Human Rights Act 1993. This could provide the basis for positive action in the area of employment and training for disabled people. Coupled with a less pervasive charity ethic, the development of what in the United States is called the rights based approach may be a catalyst for change.

The relationship between disability and the labour market has not been well researched. The reliance on numbers as a monitoring tool to measure progress presents a distorted picture because it excludes those who are not counted. Collecting quantitative data on numbers of disabled people in the population, and in the workforce is a basic necessity, but must be augmented by disaggregation, and by the gathering of qualitative data. There is a need to locate disabled people, particularly in the private sector, and undertake study to discover if people with certain kinds and levels of disability are excluded from or particularly disadvantaged in the workplace. Is the situation different if a disability is acquired while in the workforce? What effect does age of onset have on labour market expectations?

It is interesting to note that recent attempts to pass Civil Rights Legislation in the UK elicited a strong negative approach from the conservative government which used as its chief weapon a cost compliance assessment of seventeen billion pounds. The disability community responded by providing some simple cost benefit analysis of antidiscrimination legislation, based on benefit savings. Cost benefit has also been applied to another affirmative action programme, the Disability Leave initiative. There may be scope to apply this in New Zealand.

Importantly there is still the need for some basic research on costs of disability in relation to work, and the gathering of baseline data from the national census and the House- 
hold Labour Force Surveys.

\section{References}

Disability Alliance 1994 Accounting for Discrimination Estimating the Costs of excluding Disabled People from the Workforce Report London

Handy, Charles 1994 The Empty Raincoat Hutchinson London

Hunt Robyn, 1994 Reframing the Future Disabled People and Work. Unpublished Nuffield Travel Bursary report Wellington

Lonsdale, Susan 1994 Personal Interview, London

Oliver, Michael 1992 Intellectual Masturbation, A Rejoinder to Soder and Booth European Journal of Special Needs Education 7 (1) p21

Swain, John, Finkektein, Vic, French, Sally and Oliver, Mike (eds) 1993 Disabling Barriers, Enabling Environments Sage Publications and Open University London

Rights Now Campaign 1994 What Price Civil Rights? The facts behind the myths of the cost compliance Assessment London, Radar

\section{Author}

Robyn Hunt is a Manager of Review and Development for Workbridge, PO Box 1420, Wellington. 